SCIENTIFIC REPORT

\title{
Diagnosis of herpes simplex virus-1 keratitis using Giemsa stain, immunofluorescence assay, and polymerase chain reaction assay on corneal scrapings
}

\author{
S Farhatullah, S Kaza, S Athmanathan, P Garg, S B Reddy, S Sharma
}

Br J Ophthalmol 2004;88:142-144

\begin{abstract}
Aims: To evaluate three tests used routinely for the diagnosis of herpes simplex virus (HSV) keratitis.

Methods: Corneal scrapings from 28 patients with clinically typical dendritic corneal ulcer suggestive of HSV keratitis, and 30 patients with clinically non-viral corneal ulcers, were tested by (i) Giemsa stain for multinucleated giant cells, (ii) immunofluorescence assay (IFA) for HSV-1 antigen, and (iii) polymerase chain reaction (PCR) for HSV-1 DNA, by investigators masked to clinical diagnosis. The control subjects were also investigated by smears and cultures for bacteria, fungus, and Acanthamoeba.

Results: The specificity and positive predictive values of all three tests for the diagnosis of HSV keratitis were between 95-100\%. The sensitivity of IFA and PCR was $78.6 \%$ and $81.2 \%$, respectively, and the difference was not significant; however, their sensitivity and negative predictive value were significantly higher than Giemsa stain.

Conclusions: While a combination of IFA and PCR constitute the choice of tests in clinically suspected cases of HSV keratitis, multinucleated giant cells in Giemsa stain can preempt testing by IFA and PCR in otherwise atypical cases of HSV keratitis.
\end{abstract}

$\mathrm{H}$ erpes simplex virus (HSV) keratitis is a diagnostic and therapeutic challenge to the ophthalmologist. Virus isolation is considered a standard procedure for diagnosis of viral infections; however, it is a relatively time consuming procedure and depends on viable infectious material that usually needs to be transferred to a special virology laboratory for processing. ${ }^{1}$ Rapid diagnostic tests, that allow results within hours, have been reported in the past two decades. ${ }^{2}{ }^{3}$ These rapid tests have been either enzyme or fluorescence based immunological detection of HSV-1 antigen ${ }^{4}$ or polymerase chain reaction (PCR) based detection of viral DNA. ${ }^{5}$ None of these studies evaluated these tests simultaneously in a clinically well defined group of patients.

For the past 5 years we have been routinely employing a triad of tests on corneal scrapings for the diagnosis of HSV-1 keratitis in patients seen at our institute, which is a tertiary eye care centre located in south central India. The three tests include Giemsa stain, immunofluorescence assay (IFA), and PCR. The purpose of this study was to evaluate the efficacy of these three tests in the diagnosis of HSV-1 keratitis.

\section{PATIENTS AND METHODS}

Twenty eight patients shown to have clinically typical dendritic epithelial defect in the cornea with underlying subepithelial infiltrate, pathognomonic of viral keratitis, comprised the test group. Thirty patients with corneal epithelial defect with underlying stromal infiltrate with history and clinical features not suggestive of viral corneal disease, were included in the control group.

Using standard techniques, three corneal scrapings were collected under topical anaesthesia and slit lamp magnification with a sterile blade no 15 on a Bard Parker handle. Scraped material was smeared on two glass slides for Giemsa stain and IFA, and was placed in $0.5 \mathrm{ml}$ of PBS ( $\mathrm{pH} 7.2$ ) and stored at $-70^{\circ} \mathrm{C}$ until processed for PCR. The smear for Giemsa stain was stained by Diff Quick, an equivalent of Wright/Giemsa stain (Bacto Laboratories Pty, Ltd, Liverpool, NSW, Australia) for the observation of multinucleated giant cells (MNGCs) with or without lymphocytes and intranuclear inclusions.

Immunofluorescence assay (IFA) was done as described earlier. ${ }^{3}$ Smears were fixed in cold acetone and rabbit anti HSV-1polyclonal antibody (Dako, Denmark) was used as primary antibody. Secondary antibody used was FITC conjugated swine anti-rabbit immunoglobulin (Dako, Denmark). The results were assessed under a reflected light fluorescence microscope (BH2-RFC, Olympus) with cube B having filter combinations for excitation spectrum region near $490 \mathrm{~nm}$ for FITC stain. Positive staining for HSV was represented by the presence of one or more basal epithelial cells exhibiting specific bright apple green fluorescence. A presumptive negative result was indicated by the absence of fluorescence in a minimum sampling of 20 basal epithelial cells.

For PCR, the DNA was extracted from the corneal scrapings with the commercially available DNAzol solution (Helena BioSciences, UK) and precipitated in absolute ethanol and washed according to the instructions. ${ }^{7}$ Amplification region for PCR was HSV-1 gpD gene with primer position being F:19-43 and R:218-239. The primer sequences and PCR conditions were as described earlier. ${ }^{8}$

Following PCR, the amplicon (221 bp) was resolved on a $1.5 \%$ agarose/TAE gel, visualised using ethidium bromide $(0.5 \mu \mathrm{g} / \mathrm{ml})$ under ultraviolet illumination, and recorded using the ultraviolet gel documentation system (UVI Tec Ltd, Cambridge, UK). Figure 1 shows a representative gel of PCR done with two corneal scrapings from the test group along with appropriate negative and positive controls. The positive control DNA was obtained from HSV-1 ATCC, V-539, USA, grown in Vero cell line. The laboratory staff performing the tests were masked to the clinical diagnosis.

In addition to Giemsa, IFA and PCR the corneal scrapings from control subjects were also processed for bacteria, fungi, and parasites as in the method described by us earlier.'

\section{RESULTS}

There were 20 men and eight women in the test group and 16 men and 14 women in the control group. The mean age was 


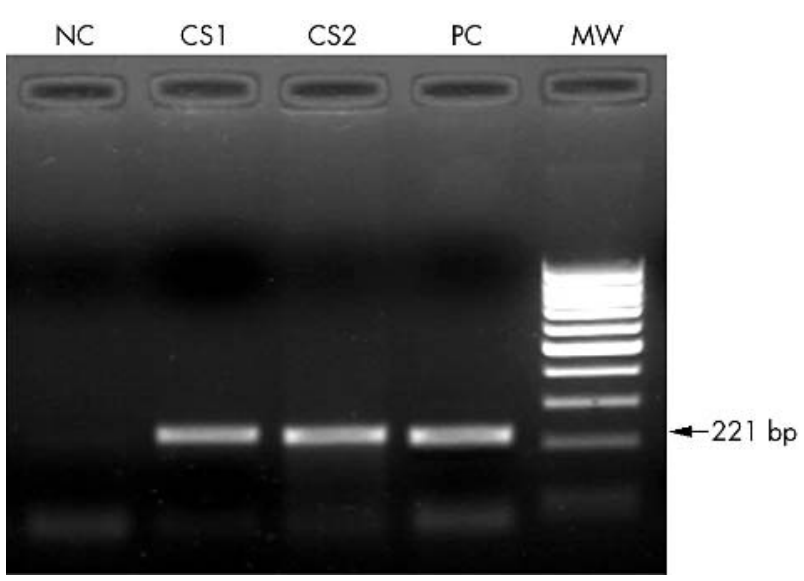

Figure 1 Representative gel showing PCR results of two corneal scrapings from test group. $\mathrm{NC}=$ negative control, $\mathrm{CS1}=$ corneal scraping $1, \mathrm{CS} 2=$ corneal scraping $2, \mathrm{PC}=$ positive control, $\mathrm{MW}=$ 100 bp ladder.

33.57 (SD 15.4) (range 1-66) years in the former and 43.84 (SD 20.6) (range 0.25-84) years in the latter. While the corneal scrapings from 13 out of 30 control subjects (43.3\%) did not grow any organism, 13 showed significant growth of bacteria, and in four cases fungi were grown. Eight of the bacterial keratitis were caused by Staphylococcus epidermidis, two by Streptococcus pneumoniae, and one each by Pseudomonas aeruginosa, Corynebacterium species, and $\beta$-haemolytic streptococci. Two out of four fungal isolates were Aspergillus flavus, while one was Cladosporium species and one was unidentified.

The results of Giemsa stain, IFA, and PCR in both test and control groups are shown in table 1. All samples from the control group were negative by Giemsa and PCR; however, one sample was reported positive in IFA. Twenty six out of 28 samples $(92.8 \%)$ in the test group were positive with PCR while IFA was positive in $78.6 \%(22 / 28)$, and MNGCs were seen in $48.1 \%$ (13/27). The specificity and positive predictive values of all three tests were in the range of $95-100 \%$. In contrast, the sensitivity and negative predictive values of the tests varied. The sensitivity of IFA and PCR was comparable ( $78.6 \%$ and $81.2 \%$ respectively, $p=0.252$ ) but the sensitivity of Giemsa stain was significantly lower than both these tests (Giemsa $v$ IFA, $\mathrm{p}=0.026$, Giemsa $v$ PCR, $\mathrm{p}=0.003$, Fisher's exact test).

\section{DISCUSSION}

A prevalence of $7.8 \%$ has been reported earlier for HSV keratitis among patients attending cornea clinic in a tertiary eye care centre in south India. ${ }^{10}$ The study included 234 out of 300 patients having clinical features suggestive of viral aetiology. Despite using procedures of viral culture and IFA

Table 1 Results of Giemsa stain, IFA, and PCR in test and control subjects

\begin{tabular}{lll}
\hline Test method & Test group $(\mathbf{n}=\mathbf{2 8})$ & Control group $(\mathbf{n = 3 0 )}$ \\
\hline Giemsa stain & 13 & 0 \\
MNGC+ & 14 & 30 \\
MNGC - & 1 & - \\
Not done & \\
IFA & 1 \\
HSV-1 antigen + & 22 & 29 \\
HSV-1 antigen - & 6 & 0 \\
PCR & 26 & 30 \\
HSV-1 DNA + & 2 & \\
HSV-1 DNA - & 2 & \\
\hline$+=$ Detected, $-=$ & not detected.
\end{tabular}

the authors achieved an overall confirmed laboratory diagnosis in only $40 \%$ of the clinically suspected patients. This indicates the difficulty in establishing laboratory diagnosis in cases suspected to be viral keratitis and the need for more sensitive techniques. PCR based techniques have been employed on tear samples, ${ }^{6}{ }^{11}{ }^{12}$ corneal epithelium, ${ }^{13}$ and corneal buttons ${ }^{14}{ }^{15}$ for the investigation of herpetic ocular diseases with a promise of greater sensitivity and specificity compared with antigen detection and viral culture methods. Although mentioned in textbooks, the older but simpler method of detection of multinucleated giant cells, lymphocytes, and inclusion bodies in Giemsa stained corneal scrapings, has not found much favour in the diagnosis of HSV keratitis. However, we recently reported its use in the diagnosis of HSV keratitis in a contact lens wearer. ${ }^{16}$

Keen to find an optimum combination of laboratory tests that may help to establish the diagnosis of HSV keratitis in suspected or atypical cases of keratitis, this study was undertaken. We chose the gold standard of clinically typical cases of HSV epithelial keratitis for evaluation of these three tests as viral isolation techniques have not been very successful in our hands. Our laboratory has been engaged in using these three tests on corneal scrapings for the diagnosis of HSV keratitis and based on our clinical correlation we consider positivity in two of the three tests essential for a confirmed diagnosis. Although a clinical diagnosis of HSV-I epithelial keratitis is relatively straightforward, the clinical features in stromal HSV keratitis can often be obscure, which may further be confounded by superadded infection with bacteria or fungus in countries such as India. The results of this study indicate all three tests to be highly specific with very high positive predictive values. We found PCR to be most sensitive, although the difference in sensitivity from IFA was statistically not significant. There was only one sample in the control group that was considered positive by IFA but there were six cases that were negative in the test group (table 1). In our hands IFA showed better sensitivity than an earlier reported study ${ }^{10}$; however, we are wary of diagnosis based on a single test and use PCR to confirm or strengthen the diagnosis. False positivity is known to be a common problem with PCR based tests ${ }^{17}$ and during routine use, one is likely to face the problem of amplicon contamination. However, the presence of DNA in negative controls invalidates a test run and requires retesting. This study confirms the excellent specificity of the assay. Its sensitivity is higher than any other currently employed test; nevertheless, sample variation may account for absence of DNA in two cases among our test group of patients accounting for less than $100 \%$ sensitivity (table 1 ).

Although the Giemsa stain did not pick up any case that was missed by IFA or PCR, we consider it a valuable test. It can provide a clue to the presence of HSV infection in an otherwise unsuspected case. Inclusion of Giemsa stain of corneal scraping is a routine procedure in the investigation of all patients seen in our cornea clinic with suspected microbial keratitis, and we recommend testing of additional corneal scrapings by IFA and PCR in all cases where MNGCs, inclusion bodies, or lymphocytes are seen in the Giemsa stained scraping. This procedure may help clinch the diagnosis in cases with atypical presentations. IFA and PCR remain the tests of choice in all suspected cases of HSV keratitis.

\section{Authors' affiliations}

S Farhatullah, S Athmanathan, S B Reddy, S Sharma, Jhaveri Microbiology Center, Professor Brien Holden Eye Research Center, Hyderabad Eye Research Foundation, LV Prasad Eye Institute, LV Prasad Marg, Banjara Hills, Hyderabad - 500 034, India 
S Kaza, P Garg, Cornea Services, LV Prasad Eye Institute, LV Prasad Marg, Banjara Hills, Hyderabad - 500 034, India

Correspondence to: Savitri Sharma, MD, Jhaveri Microbiology Center, LV Prasad Eye Institute, LV Prasad Marg, Banjara Hills, Hyderabad - 500 034, India; savitri@lvpeye.org

Accepted for publication 16 April 2003

\section{REFERENCE}

1 Lennette EM. In: Laboratory diagnosis of viral infections. New York: Marcel Dekker Inc, 1992.

2 Kowalski RP, Gordon YJ. Evaluation of immunologic tests for the detection of ocular herpes simplex virus. Ophthalmology 1989;96:1583-6.

3 Thiel MA, Bossart W, Bernaver W. Improved impression cytology techniques for the immunopathological diagnosis of superficial viral infections. Br J Ophthalmol 1997;81:984-8.

4 Asbell PA, Torres M A, Kamenar T, et al. Rapid diagnosis of ocular herpes simplex infections. Br J Ophthalmol 1995;79:473-5.

5 Berra A, Dutt JE, Foster CS. Detection of herpes simplex virus type- 1 by an in situ polymerase chain reaction technique. Cornea 1996;15:55-61.

6 Koizumi N, Nishida K, Adachi W, et al. Detection of herpes simplex virus DNA in atypical epithelial keratitis using polymerase chain reaction. Br J Ophthalmol 1999;83:957-60.

7 Ausubel FM, Brent R, Kingston RE, et al. Current protocols in molecular biology. New York: John Wiley, 1990;Vol 2:A.1.5.
8 Aurelius $\mathbf{E}$, Johansson B, Skoldenberg B, et al. Encephalitis in immunocompetent patients due to herpes simplex virus type-1 or 2 as determined by type-specific polymerase chain reaction and antibody assays of cerebrospinal fluid. J Med Virol 1993;39:179-86.

9 Kunimoto DY, Sharma S, Garg P, et al. Corneal ulceration in the elderly in Hyderabad, south India. Br J Ophthalmol 2000;84:54-9.

10 Pramod NP, Rajendran P, Kannan KA, et al. Herpes simplex keratitis in south India: clinico-virological correlation. Jpn J Ophthalmol 1999;43:303-7.

11 Shimomura Y, Yamamoto S, Yao Y, et al. Herpes simplex virus DNA detection from tear film of herpetic keratitis in non-active stage. Nihon Ganka Kiyo (Folia Ophthalmol Jpn) 1993;45:481-3.

12 Yamamoto S, Shimomura Y, Kinoshita S, et al. Detection of herpes simplex virus DNA in human tear film by the polymerase chain reaction. Am J Ophthalmol 1994:117:160-3.

13 Kowalski RP, Gordon YJ, Romanowski EG, et al. A comparison of enzyme immunoassay and polymerase chain reaction with the clinical examination for diagnosing ocular herpetic disease. Ophthalmology 1993;100:530-3.

14 Laycock KA, Lee SF, Stulting RD, et al. Herpes simplex virus type 1 transcription is not detectable in quiescent human stromal keratitis by in situ hybridization. Invest Ophthalmol Vis Sci 1993;34:285-92.

15 Shimomura $Y$, Mori Y, Inoue $Y$, et al. Herpes simplex virus latency in human cornea. Jpn J Ophthalmol 1993;37:1808-15.

16 Sreedharan A, Veenashree MP, Pasricha G, et al. Atypical Herpes simplex keratitis (HSK) presenting as a perforated corneal ulcer with a large infiltrate in a contact lens wearer: multinucleated giant cells in the Giemsa offered a clue to the diagnosis. BMC Ophthalmology 2001;1:1, (www.biomedcentral.com/1471-2415/1/1).

17 Sharma S, Das D, Anand R, et al. Reliability of nested PCR in the diagnosis of bacterial endophthalmitis. Am J Ophthalmol 2002;133:142-4. 